\title{
Mario Lavagetto, Improvvisamente uno sconosciuto
}

\section{Marco Stupazzoni}

\section{(2) OpenEdition}

\section{Journals}

\section{Edizione digitale}

URL: http://journals.openedition.org/studifrancesi/36411

DOI: 10.4000/studifrancesi.36411

ISSN: 2421-5856

\section{Editore}

Rosenberg \& Sellier

\section{Edizione cartacea}

Data di pubblicazione: 1 juillet 2005

Paginazione: 184-185

ISSN: 0039-2944

\section{Notizia bibliografica digitale}

Marco Stupazzoni, «Mario Lavagetto, Improvvisamente uno sconosciuto», Studi Francesi [Online], 145

(XLIX | I) | 2005, online dal 30 novembre 2015, consultato il 18 avril 2021. URL: http://

journals.openedition.org/studifrancesi/36411 ; DOI: https://doi.org/10.4000/studifrancesi.36411

\section{Questo documento è stato generato automaticamente il 18 avril 2021.}

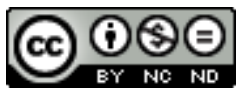

Studi Francesi è distribuita con Licenza Creative Commons Attribuzione - Non commerciale - Non opere derivate 4.0 Internazionale. 


\title{
Mario Lavagetto, Improvvisamente uno sconosciuto
}

\author{
Marco Stupazzoni
}

\section{NOTIZIA}

MARIO LAVAGETTO, Improvvisamente uno sconosciuto, in Lavorare con piccoli indizi, Torino, Bollati Boringhieri, 2003 («Nuova Cultura» n 96), pp. 199-223.

1 Spesso il lettore di grandi macchine narrative come i romanzi della Comédie humaine si trova all'improvviso a fare i conti con segnali minimi, con particolari indiziari apparentemente trascurabili e insignificanti, ma che, al contrario, orientano e determinano, in una sorta di patto narrativo tra autore e lettore, la struttura e l'orizzonte di attesa del testo.

2 In queste penetranti pagine, che costituiscono il tessuto di un saggio fino ad oggi inedito, Mario Lavagetto riflette sul rilievo metanarrativo della figura dell'inconnu nel romanzo balzachiano: questo personaggio, identificabile a seconda delle circostanze nello straniero, nello sconosciuto o nel flâneur, che improvvisamente fa il suo ingresso sulla scena del racconto, rappresenta, a giudizio dell'A., «l'equivalente antropomorfico dell'enigma, del mistero /.../ intorno a cui ruota un'infinità di mondi possibili» (p. 199) e di "possibilità romanzesche" pressoché infinite. L'alta frequenza di questa figura letteraria variabile e transitoria nell'universo letterario balzachiano porta Lavagetto a delineare i fondamenti tipologici e fenomenologici dell'inconnu in Balzac, attraverso l'analisi di un denso corpus di romanzi e di racconti della Comédie humaine (da La Peau de chagrin al Député d'Arcis). L'incertezza e il ritardo del riconoscimento di personaggi (o di categorie di personaggi), che emergono a fatica dal territorio d'ombra dell'anonimato e della precarietà perché momentaneamente privi di nome o celati dietro falso nome, propongono quasi sempre al lettore un enigma che ricalca un'esperienza antropologica e che si configura, allo stesso tempo, come una provocazione, come il perno di 
un'attività romanzesca «potenzialmente infinita» (p. 220) che evoca «una costellazione di romanzi possibili» (p. 223). 